Article

\title{
Study of Deformation Law of Casing Local Lateral Collapse Based on the Principle of Virtual Work
}

\author{
Wanchun Zhao ${ }^{1,2}$, Jing Ge ${ }^{3}$, Ranjith Pathegama Gamage ${ }^{2}{ }^{-}$, Yuwei $\mathrm{Li}^{3}$, Zhenlong Song ${ }^{2,4}$ \\ and Tingting Wang ${ }^{2,5,6, *}$ \\ 1 Institute of Unconventional Oil \& Gas, Northeast Petroleum University, Daqing 163318, Heilongjiang, China; \\ zhaowanchun@nepu.edu.cn \\ 2 Deep Earth Energy Laboratory, Department of Civil Engineering, Monash University, Building 60, \\ Melbourne, Victoria 3800, Australia; ranjith.pg@monash.edu (R.P.G.); songzl@sustech.edu.cn (Z.S.) \\ 3 School of Petroleum Engineering, Northeast Petroleum University, Daqing 163318, Heilongjiang, China; \\ gesaki@163.com (J.G.); liyuweibox@126.com (Y.L.) \\ 4 State Key Laboratory of Coalmine Disaster Dynamics and Control, Chongqing University, \\ Chongqing 400030, China \\ 5 School of Electrical Engineering \& Information, Northeast Petroleum University, \\ Daqing 163318, Heilongjiang, China \\ 6 Heilongjiang Provincial Key Laboratory of Networking and Intelligent Control, \\ Daqing 163318, Heilongjiang, China \\ * Correspondence: wangtingting@nepu.edu.cn
}

Received: 14 August 2019; Accepted: 24 September 2019; Published: 28 September 2019

check for updates

\begin{abstract}
In view of the water swelling of mudstone and the creep induction function of formations in the process of oilfield water injection, the casing incurs collapse deformation under local lateral load. In this study, according to the actual collapse deformation characteristics of the casing in the second section of the Qing formation of the Songliao Basin in China, the yield surfaces of the casing collapse deformation are considered as plane plastic areas (half rhombus) with symmetric parabola shaped boundaries, and a mechanical model for the local lateral collapse deformation of casing is presented based on the principle of virtual work. Four types of casing, $4 \frac{1}{2}{ }^{\prime \prime} \mathrm{J} 55,5 \frac{1}{2}{ }^{\prime \prime} \mathrm{J} 55,4 \frac{1}{2}{ }^{\prime \prime} \mathrm{N} 80$ and $5 \frac{1}{2}$ "N80, are selected as examples. The relation of the casing intensity, the absolute reduction of intensity and the relative reduction ratio of intensity change with casing wall thickness, yield stress, radial maximum deformation, and deformation length are calculated and analyzed. The results show that the casing intensity of the casing is reduced under local lateral load, which is lower than the design standard value of the American Petroleum Association specification (API SPEC) 5CT. The relative reduction ratio declines linearly with the wall thickness of the casing wall as the yield stress increases, and increases linearly with increasing maximum deformation. In addition, the local lateral bearing capacity of the casing reaches the minimum value when the plastic deformation length reaches the critical value or the deformation quantity is less than the critical value. The conclusions provide scientific guidance for preventing casing failure accidents caused by deformation.
\end{abstract}

Keywords: casing collapse; local lateral load; principle of virtual work; Jilin oilfield

\section{Introduction}

The problem of casing failure has a critical effect on the working lifetime of oil and gas wells and restricts the efficiency mining of oil and gas and reservoir construction. There have been serious casing failure problems in conventional and unconventional oil and gas fields [1-5].

Casing strength design is the precondition for researchers to prevent casing failure. In the 1940s, the Soviet Union mainly used the formula Gina as the reference standard for the design of 
casing strength. In the 1950s, G.M. Sarji Soe considered the influence of ovality and wall thickness of casing, and established a calculation standard for casing collapse strength which was adopted as the national standard. By the mid-1970s, most countries used API (American Petroleum Association) [6] specification as the calculation standard of casing strength. At present, in order to optimize casing design, an amount of important research achievements on the collapse strength of casing under uniform and non-uniform loads have been made [7-12], from which some standards have been formed such as the API 5C3 and ISO 10400. Although the API 5C3 and ISO 10400 [13] standards have presented the prediction models and been adopted by the world oil industry, mechanical models based on two standards are not suitable for strength criteria or prediction of casings under special conditions in the process of strength design. Therefore, in view of some complex formation conditions and drilling and production technology, some special forms of casing failure problems have not yet been solved [14-17]. The problem of casing collapse deformation under the lateral load of the Qing second formation in Jilin oilfield is shown in Figures 1 and 2. The casing failures of the Qing second formation in Songliao Basin are serious. The proportion of wells with such casing failure in Jilin oilfield is shown in Figure 3 [18].

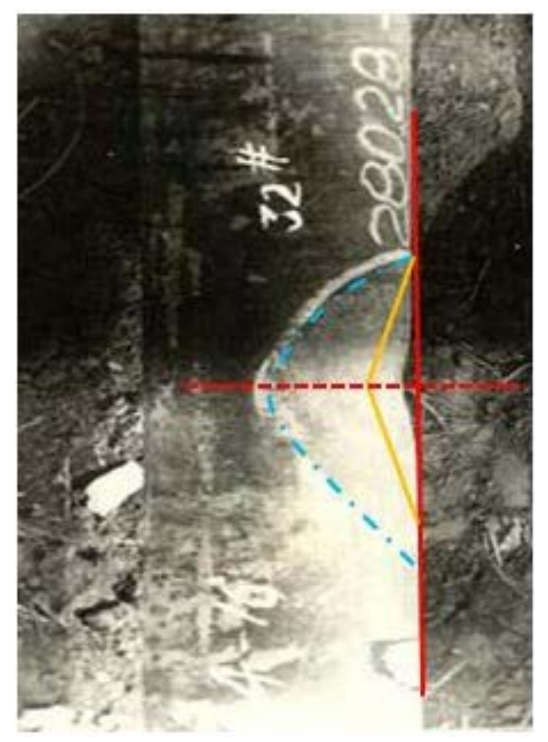

Figure 1. Deformation of casing collapse (collapse deformation at one end, Jilin oilfield, China).

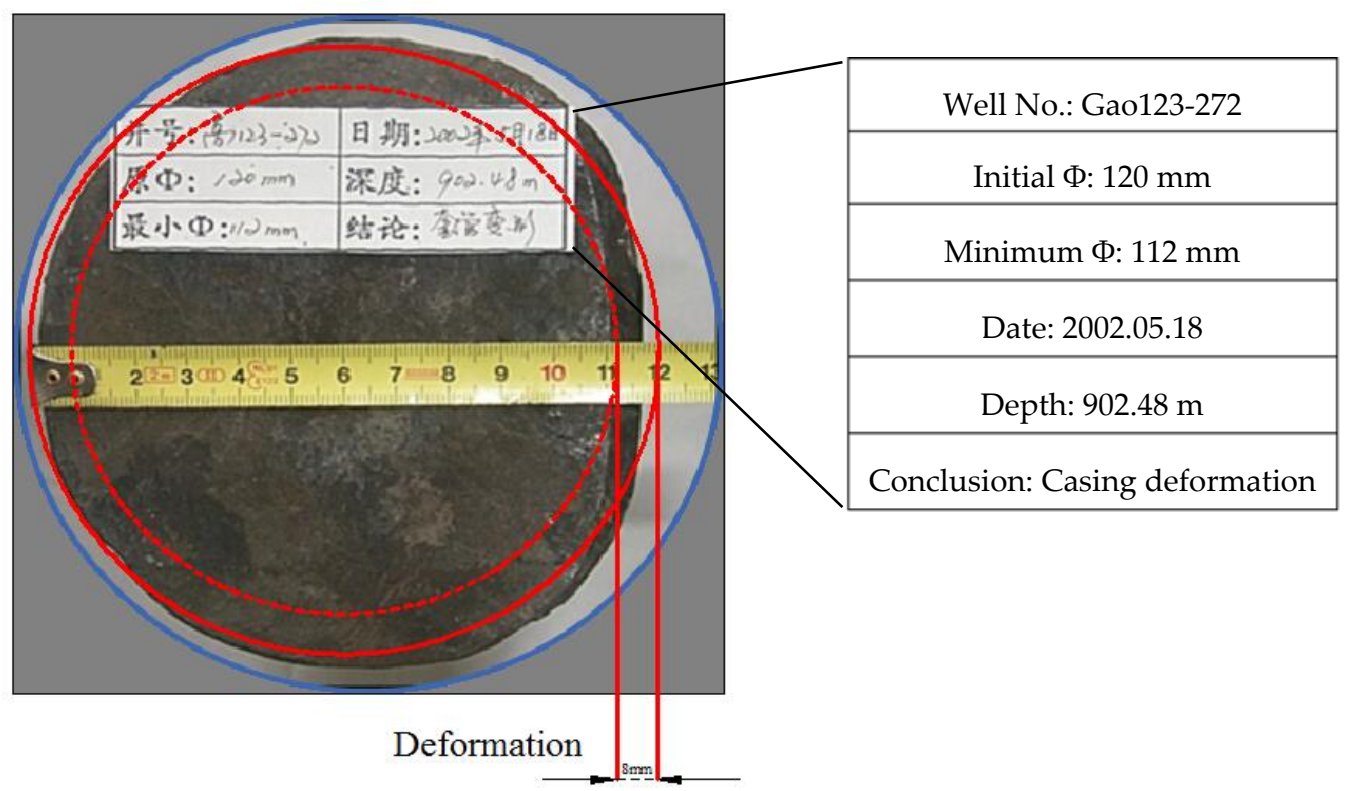

Figure 2. Lead print (collapse deformation at one end of the casing string, Jilin oilfield, China). 


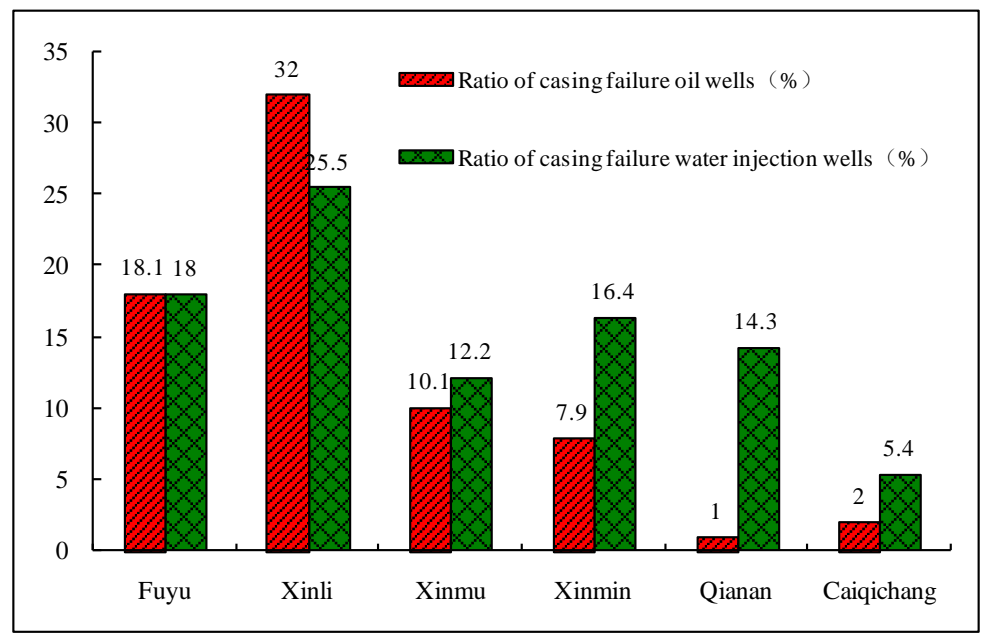

Figure 3. The ratio of casing failure wells in different areas of Jilin oilfield in China.

The study found that the main external causes of casing collapse is lateral local load formed since the mudstone expands with water absorption and formation creep in the Qing second formation [19-21]. The boundary shape of deformation casing collapse area based on data statistics is shown in Figures 4 and 5 . The radial deformation is an approximate half rhombus, and area boundaries of are approximate symmetric parabolas. In addition, Jones et al. [22] reported that the bottom of the deformed area of cylindrical shells with fixed ends under lateral load also present a plane shape through theoretical analysis and experimental results. Therefore, in the present study, according to the actual collapse deformation characteristics of the casing in the Jilin oilfield, the yield surface of the casing collapse deformation is considered as a plane plastic zone with an arc-shaped boundary. A mechanical model of casing collapse under local lateral load is presented, based on the principle of virtual work [23-25]. Taking the J55 and N80 type casings used in the oilfield as the research objects, the casing deformation law under local lateral load was analyzed and compared with the API 5C3 standard for casing strength. The relationship between the change of deformation quantity and deformation length for different types of casings with lateral load strength was determined by analyzing the extent of decline of the strength when the casings deform under lateral load.

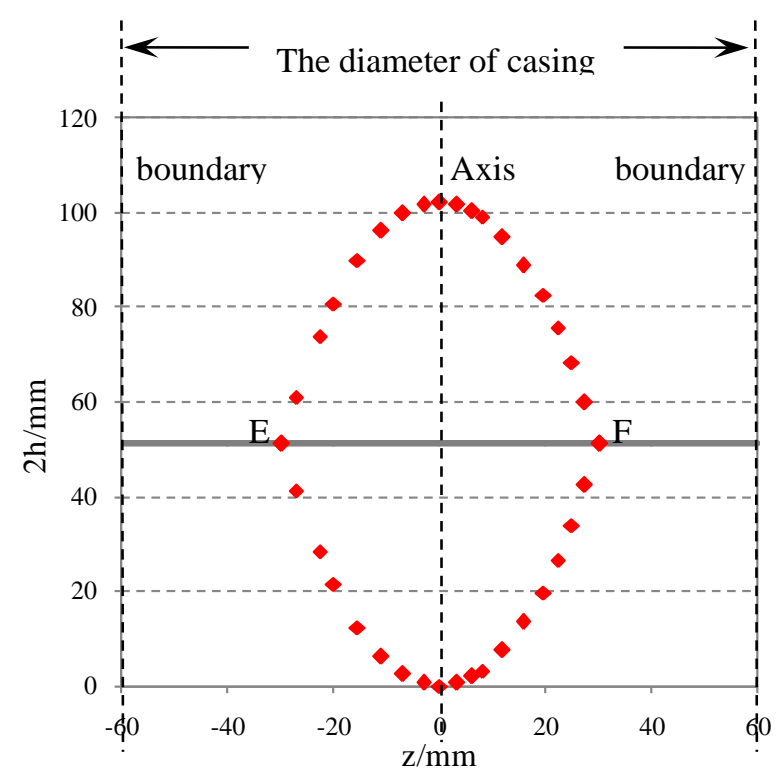

Figure 4. Side view of casing collapse deformation (Jilin oilfield, China). 


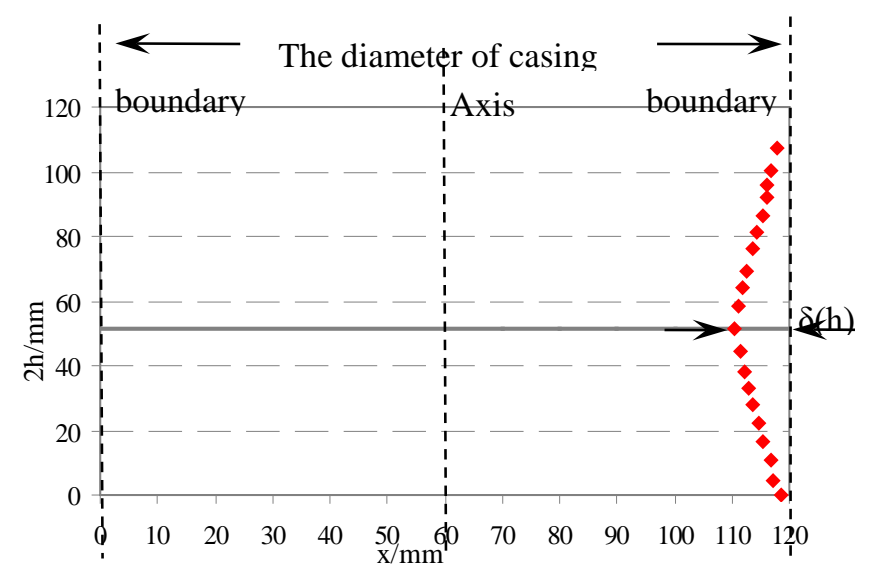

Figure 5. Front view of casing collapse deformation (Jilin oilfield, China).

The calculation results show that under the action of local lateral load, the bearing capacity of casing failure decreases. Casing strength design based on current API 5C 3 standard cannot meet the requirements of engineering, so it is necessary to design casing strength according to local lateral load. The conclusions provide scientific guidance for designing the casing string and preventing casing failure in the future, and also provides a scientific basis for further improving API strength design standards.

\section{Stress State of Downhole Casing and Mechanical Model}

\subsection{Mechanical Behavior of Casing Collapse Under Lateral Load}

According to the mechanical state of casing in Figure 6, formation 1, formation 2 and formation 3 represent different layers of rock. The gap between the casing and the formation is cemented by the cement, and the casing, cement sheath and formation form a combination, the top view of which is shown in Figure 7. In the actual formation of the Jilin oilfield, formation 1 and formation 3 are sandstone formations, and formation 2 is a rock formation with high mudstone content. In general, formation 2 is bound by adhesive to form a perfect cement layer when drilling is below formation 2. However, a gap exists between the cement ring and the formation due to the underdeveloped cementing quality, which results in channeling between the oil and the groundwater, and the groundwater enters formation 2 . The formation 2 absorbs water causing it to swell and creep deformation to occur; squeezed by the rock layers above and below, the local lateral load is finally formed.

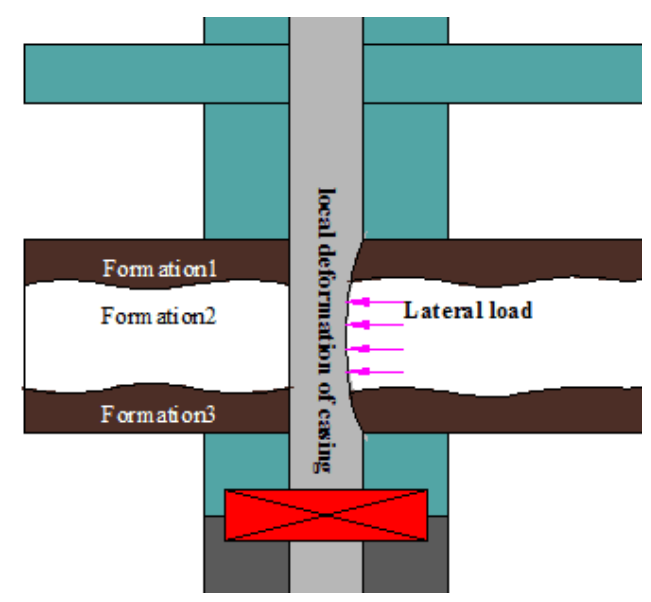

Figure 6. Schematic diagram of local deformation of casing under lateral load. 


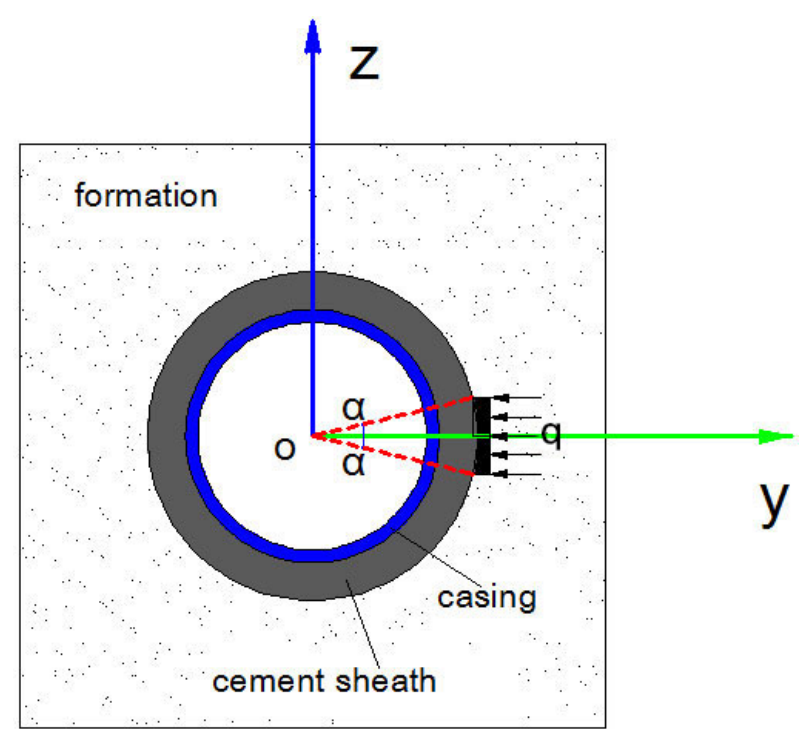

Figure 7. Top view of casing-cement sheath-formation combination.

\subsection{Mechanical Model of Casing Under Local Lateral Load}

\subsubsection{Geometric Characteristics of Casing Deformation and Assumptions}

According to the shrinkage failure and mechanical state of the casing under the local lateral load in the actual conditions of oilfields shown in Figures 6 and 7, the mechanical model of the casing can be regarded as a cylindrical and thin-walled metal tube with a fixed support at both ends. The physical and mechanical model of deformation under local lateral load is shown in Figure 8. According to the mechanical model in Figure 8, the deformation characteristics of the deformation curve boundaries $\mathrm{AFB}$ and $\mathrm{AEB}$ and the maximum deformation curve AGB determine the degree of failure of the casing, as shown in Figure 9. In this paper, the mechanical calculation chart for casing collapse deformation under lateral load on the casing was established based on the examples of casing collapse in Figures 4 and 5, as shown in Figure 8, where the lateral deformation curve boundaries AFB and AEB are arc-shaped, the plastic deformation surface $S_{\text {AFBEA }}$ is a plane, point $G$ is the center of the deformed surface, and line AG and line GB are the broken lines, as shown in Figure 9.

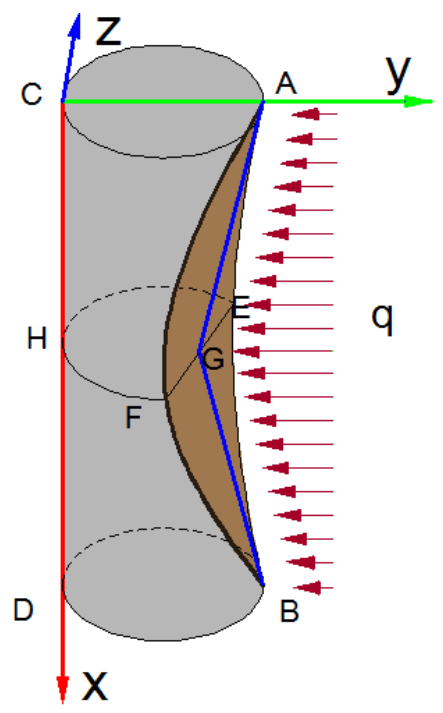

Figure 8. Diagram of casing deformation under lateral load. 


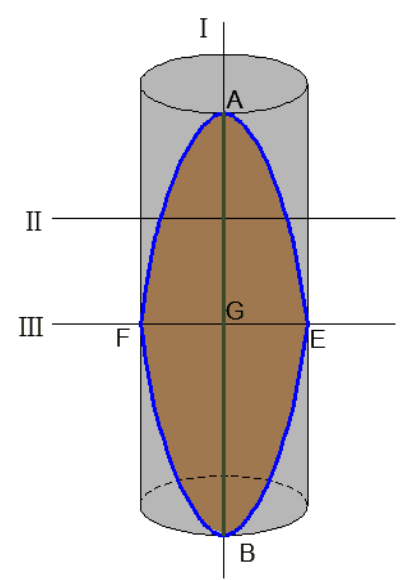

Figure 9. Projection in direction of plastic deformation zone $(-y)$ of metal tube.

According to the mechanism of mechanical deformation in Figures 8 and 9, the assumptions made concerning the research objects are as follows:

(1) The deformation constitutive relationship of the thin-walled metal tube material under local lateral load satisfies the ideal rigid plastic deformation, and the compressive deformation of the material is negligible. That is to say, the interface perimeter of the thin-walled metal short tube is equal in the pre- and post-deformation.

(2) The bending and rotation of a short cylindrical tube under lateral loads are not considered.

(3) The depth of the depression in the deformed area varies continuously along the $X$-axis. The side of the deformed depression is curved and the bottom of the depression is planar.

(4) The section of the casing tube after deformation is an arc-shaped curved section, and the equal-area axis after plastic deformation passes through the center of the circular section before deformation.

\subsubsection{Geometric Relationship of Model}

This paper assumes that the casing diameter is $\mathrm{d}$, the tube radius is $\mathrm{r}$ before deformation, the maximum deformation quantity of the tube under lateral load is $\delta(h)$, the deformation circular boundary point is $E^{\prime}, F^{\prime}$ and $G^{\prime}$ before deformation, the deformation circular boundary point is $E, F$ and $G$, after deformation, the tube radius is $\widetilde{r}$ after deformation, the centers of the circle are $O / O^{\prime}$ preand post-deformation respectively, and the angles between the boundary and the main deformation axis are $\alpha(h), \alpha(h)$ and $\alpha(h)^{\prime}$ pre- and post-deformation respectively (refer to Figures 10-12).

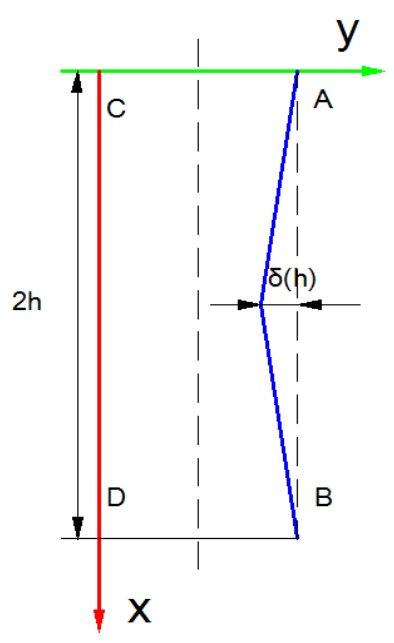

Figure 10. Profile in I-I direction. 


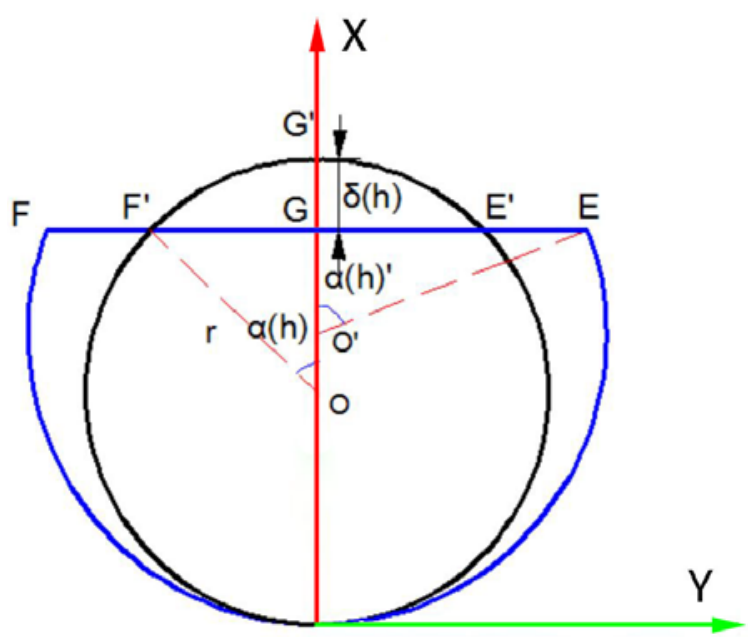

Figure 11. Profile in II-II direction.

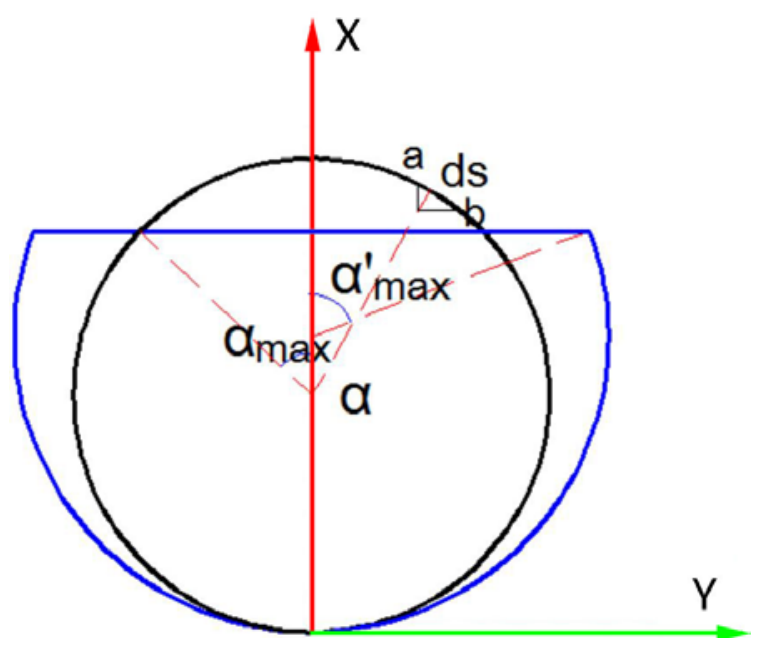

Figure 12. Profile in III-III direction.

According to the geometric relationship in Figures 9-12 and the assumed condition (1) in this paper, we can obtain:

$$
2 \pi r=l_{E F}+2 \operatorname{rarcsin} \frac{d-\delta(h)}{r}+\pi r
$$

where $l_{E F}$ is the chord length between point $E$ and point $F$ after deformation. Arranging Equation (1), we obtain:

$$
l_{E F}=\pi r\left\{1-\frac{2 \arcsin [(r-\delta) / r]}{\pi}\right\}
$$

From this, the coordinates of point $A$, point $B$, point $E$, point $F$ and point $G$ can be obtained:

$$
\left\{\begin{array}{c}
A(0, d, 0) \\
B(2 h, d, 0) \\
E\left(h, d-\delta(h), \frac{l_{E F}}{2}\right) \\
F\left(h, d-\delta(h),-\frac{l_{E F}}{2}\right) \\
G(h, d-\delta(h), 0)
\end{array}\right.
$$

According to assumed condition (2), the parameters satisfy the following geometric relationships: 


$$
\begin{gathered}
\alpha(h)=\arccos \left(\frac{r-\delta(h)}{r}\right) \\
r^{\prime}=\frac{\pi r-\left(\pi-\alpha(h)^{\prime}\right) r^{\prime}}{\sin \alpha(h)^{\prime}} \\
r^{\prime} \sin \alpha(h)^{\prime}=r \alpha(h) \\
r^{\prime} \cos \alpha(h)^{\prime}=(r-\delta(h))-\left(r^{\prime}-r\right) \\
\alpha(h)^{\prime}=\arctan \left[\frac{r \alpha(h)}{r-\delta(h)}\right]
\end{gathered}
$$

According to assumed condition (3), the continuity equation from point $A$ to point $G$ of the tube is:

$$
y=y(x)
$$

According to the conditions assumed in this paper, the plastic zone of the tube formed under the external load is a plane. Consequently, the continuity equation of Equation (9) is:

$$
y(x)=\frac{\delta(h)}{h} \cdot x
$$

In the same way, the continuity equation from point $A$ to point $E$ of the tube is:

$$
z=z(x)
$$

According to the conditions assumed in this paper, the boundary of the plastic deformation zone is arc-shaped, and the arc-shape can be regarded as a part of the parabolic equation. Accordingly, Equation (11) can be expressed as follows:

$$
z(x)=(m x+n)^{2}+k
$$

According to the coordinate relation among point $A$, point $B$ and point $E$, Equation (12) can be expressed as follows:

$$
z(x)=-\left(\frac{\sqrt{r \cdot \alpha(h)}}{h} x-\sqrt{r \cdot \alpha(h)}\right)^{2}+r \cdot \alpha(h)
$$

\section{Calculation of Virtual Work for Pipe String Deformation}

\subsection{Principle of Virtual Work}

The principle of virtual work represents the equilibrium equation of the particle system in the form of virtual work [26,27], and it can be expressed that the indispensable condition and sufficient condition for a particle system to be in equilibrium with ideal constraint is the sum of the elementary work that the active force works on the virtual displacement of the particle system is zero [28]. The model in this paper satisfies the principle of virtual work, and assumes that the work of internal force is negative while the work of external force is positive in the process of casing deformation. The work of internal force is equal to the work of external force when the casing incurs plastic deformation under local lateral uniform load according to the principle of virtual work [29].

According to the above description, the following equation can be obtained:

$$
W_{\mathrm{ex}}=W_{\text {in }}
$$


where $W_{\text {ex }}$ is the virtual work that the local partial uniform load works on the casing, $W_{\text {in }}$ is dissipative work that the casing overcomes the plastic deformation [30-32] created by internal force.

\subsection{Work Done by Internal Force and External Force in Pipe String Deformation}

3.2.1. Dissipative Work Done by Internal Force from Which the Casing Overcomes Plastic Deformation

(1) Plastic dissipative work $W_{1}$ when the plastic zone changes from the cylindrical surface to a flat surface.

According to the conditions assumed in this paper, the plastic dissipative work when the casing changes from the cylindrical surface to an arc-shaped surface under local partial load is:

$$
W_{1}=2 \int_{0}^{h} W_{\mathrm{s}} \mathrm{d} x
$$

where $W_{\mathrm{s}}$ is the dissipative work on any arc length ds.

According to the geometric relationship in Figure 10, the dissipative work $W_{\mathrm{s}}$ on any given arc length ds is:

$$
d W_{s}=2 N_{0} \alpha d s
$$

where $N_{0}$ is the ultimate axial force of the deformation mechanism [33-35].

According to the assumed conditions, the ultimate axial force can be expressed as:

$$
N_{0}=\frac{\sigma_{0} D^{2}}{4}
$$

where $\sigma_{0}$ is the yield strength of tube material, and $D$ is the wall thickness of the tube.

The dissipative work on the whole arc $\widehat{K L}$ is:

$$
W_{s}=2 \int_{0}^{s} N_{0} \alpha d s=2 \int_{0}^{\alpha(x)} 2 N_{0} r \alpha d \alpha=\frac{\sigma_{0} D^{2} r \alpha^{2}(x)}{2}
$$

where $\alpha(x)$ is the angle between the line from the plastic zone boundary to the center and the concave direction when any section ranges from a cylindrical surface to a flat surface.

The concave depth is continuously changed along the direction of the $X$ axis. In the process of changing from $x=0$ to $x=1$ obtained by Equation (4), $\alpha(x)$ on any section satisfies the relationship:

$$
\alpha(x)=\arccos \frac{(r-\delta(x))}{r}
$$

where $\delta(x)$ is the concave depth on any section.

According to the binding relationship in Figure 10 and the assumed conditions, the following relation is obtained:

$$
\frac{\delta(x)}{\delta(h)}=\frac{x}{h}
$$

Substituting Equation (19) and Equation (20) into Equation (18), $W_{\mathrm{s}}$ on any section can be obtained:

$$
W_{s}=\frac{2 \sigma_{0} D^{2}}{4} r \cdot\left[\arccos \left(1-\frac{\delta(h)}{r h} x\right)\right]^{2}
$$

According to Equations (18)-(20), Equation (15) can be expressed as follows: 


$$
\begin{aligned}
& W_{1}=2 \int_{0}^{h} W_{\mathrm{s}} \mathrm{d} x=2 \int_{0}^{h} \frac{2 \sigma_{0} D^{2}}{4} \cdot r \cdot\left[\arccos \left(1-\frac{\delta(h)}{r \cdot h} x\right)\right]^{2} \mathrm{~d} x \\
& =-\sigma_{0} D^{2} r^{2} \frac{h}{\delta(h)}\left[\left(1-\frac{\delta(h)}{r}\right) \arccos ^{2}\left(1-\frac{\delta(h)}{r}\right)-2 \sqrt{1-\left(1-\frac{\delta(h)}{r}\right)^{2}}+\frac{2 \delta(h)}{r}-4\right]
\end{aligned}
$$

(2) Plastic dissipative work $W_{2}$ when the surface curvature radius changes in the plastic zone.

The computational method of the plastic dissipative work $W_{2}$ when the surface curvature radius changes in the plastic zone is similar to that of the plastic dissipative work $W_{1}$ when the plastic zone changes from a cylindrical surface to a flat surface.

$$
W_{2}=2 \int_{0}^{h} \frac{2 \sigma_{0} D^{2}}{4} \cdot r \cdot(\pi-\alpha(x))\left(\alpha(x)^{\prime}-\alpha(x)\right) \mathrm{d} x
$$

where, $\alpha(x)^{\prime}$ is the angle between the line from the boundary of any section to the center and the concave direction when the surface curvature radius changes, as shown in Figure 11.

According to Equation (6) and Equation (7), we can obtain:

$$
\alpha(x)^{\prime}=\arcsin \left(\frac{2 \alpha(x) \cdot r \cdot(d-\delta(x))}{\alpha(x)^{2} \cdot r^{2}+(d-\delta(x))^{2}}\right)
$$

According to the boundary conditions, $\alpha(x)=\alpha(h)$ and $\alpha(x)^{\prime}=\alpha(h)^{\prime}$ when $x=h$, Equation (24) can be obtained and substitute it into the Equation (23).

(3) Plastic dissipative work $W_{3}$ under axial tension in the plastic zone.

The ultimate bending moment $M_{0}$ can be expressed as follows under local lateral uniform load in the plastic deformation zone [36,37]:

$$
M_{0}=\sigma_{0} D
$$

According to the fundamental equation of dissipative work under axial tension [38], the plastic dissipative work $\mathrm{W}_{3}$ under axial tension in the plastic zone can be expressed as:

$$
W_{3}=\int_{0}^{\Delta l} N_{0} \mathrm{~d} l
$$

where $\Delta l$ is the axial tensile increment in the deformed zone. Based on the geometric relationship in Figure $8, \Delta l$ is:

$$
\Delta l=\overline{G A}-h
$$

As shown in Figure 7, the length of space curve $\widehat{G A}$ is:

$$
\overline{G A}=\sqrt{h^{2}+[\delta(h)]^{2}}
$$

By re-arranging Equation (28), we obtain:

$$
W_{3}=\frac{2 \sigma_{0} D^{2}}{4}\left(\sqrt{h^{2}+[\delta(h)]^{2}}-h\right)
$$

(4) Plastic dissipative work $W_{4}$ when the yield line $\overline{E F}$ rotates.

The plastic dissipative work $W_{4}$ when the yield line of plastic deformation $\overline{E F}$ is constituted by the plastic hinge $E$ and the plastic hinge $F$ can be expressed as follows:

$$
W_{4}=N_{0}(\pi-2 \beta) \cdot \overline{E F}
$$

According to the parameter relation in Figure 10, Equation (30) can also be expressed as follows: 


$$
W_{4}=\frac{\sigma_{0} D^{2}}{4}(\pi-2 \beta) \cdot 2 r^{\prime} \cdot \sin \left((\alpha(h))^{\prime}\right)
$$

(5) Plastic dissipative work $W_{5}^{E A}$ when the yield line $\widehat{E A}$ rotates.

The plastic dissipative work $W_{5}^{E A}$ when the yield line of plastic deformation $\widehat{E A}$ constituted by the plastic hinge $\mathrm{E}$ and the plastic hinge A can be expressed as follows:

$$
\widehat{W_{5}^{E A}}=\int_{0}^{\widehat{E A}} M_{0} \alpha(x)^{\prime} \mathrm{d} x
$$

By substituting Equation (16) and Equation (24) into Equation (32), Equation (33) can be obtained:

$$
\widehat{W_{5}^{E A}}=\int_{0}^{\widehat{E A}} \frac{\sigma_{0} D^{2}}{4} \arcsin \left(\frac{2 \alpha(x) \cdot r \cdot(d-\delta(x))}{\alpha(x)^{2} \cdot r^{2}+(d-\delta(x))^{2}}\right) \mathrm{d} x
$$

According to the geometric relation, the length of the space curve $\widehat{E A}$ is:

$$
\widehat{E A}=\int_{0}^{h} \sqrt{1+\left(\frac{\partial y(x)}{\partial x}\right)^{2}+\left(\frac{\partial z(x)}{\partial x}\right)^{2}} \mathrm{~d} x
$$

In the same way, the plastic dissipative work can be obtained when the yield lines $\widehat{A F}, \widehat{F B}$ and $\widehat{B E}$ rotate, and Equation (35) can be obtained based on mirror symmetry:

$$
W_{5}^{\widehat{E A}}=W_{5}^{\widehat{A F}}=W_{5}^{\widehat{E B}}=W_{5}^{\widehat{B E}}
$$

Consequently, the total dissipative work when the plastic hinge lines rotate is as follows:

$$
W_{5}=W_{5}^{\widehat{E A}}+W_{5}^{\widehat{A F}}+W_{5}^{\widehat{F B}}+W_{5}^{\widehat{B E}}
$$

Therefore, the work done by internal force is:

$$
W_{\text {in }}=W_{1}+W_{2}+W_{3}+W_{4}+W_{5}
$$

\subsubsection{Work Done by External Force}

According to the mechanical state of casing in Figure 6, the work done by external force when the casing is under lateral load can be expressed as follows:

$$
W_{\mathrm{ex}}=\int_{0}^{h} \int_{0}^{y(h)} q \delta(h) \mathrm{d} x \mathrm{~d} y=q V_{d e f}
$$

where $\mathrm{q}$ is the local lateral load, and $V_{\text {def }}$ is the plastic deformation volume of the casing under external load.

According to the geometric deformation relation, the plastic deformation volume $V_{d e f}$ can be expressed as follows:

$$
V_{\text {def }}=2 \int_{0}^{l}\left(\pi r^{2} \cdot \frac{2 \alpha(x)}{2 \pi}-\frac{2 \cdot r \cdot \sin \alpha(x) \cdot r \cdot \cos \alpha(x)}{2}\right) \mathrm{d} x
$$




\subsubsection{Virtual Work Relation of Casing Deformation}

According to Equation (14) in relation to the virtual work relationship, by combining and arranging Equations (37) and (38), the mathematical expression of Equation (40) can be obtained as follows:

$$
\begin{aligned}
& q \cdot 2 \int_{0}^{l}\left(\pi r^{2} \cdot \frac{2 \alpha(x)}{2 \pi}-\frac{2 \cdot r \cdot \sin \alpha(x) \cdot r \cdot \cos \alpha(x)}{2}\right) d x \\
& =2 \int_{0}^{h} \frac{2 \sigma_{0} D^{2}}{4} \cdot r \cdot\left[\arccos \left(1-\frac{\delta(h) \cdot x}{r \cdot h}\right)\right]^{2} d x+ \\
& 2 \int_{0}^{h} \frac{2 \sigma_{0} D^{2}}{4} \cdot r \cdot(\pi-\alpha(x))\left(\alpha(x)^{\prime}-\alpha(x)\right) d x+ \\
& \frac{2 \sigma_{0} D^{2}}{4}\left(\sqrt{h^{2}+[\delta(h)]^{2}}-h\right)+\frac{2 \sigma_{0} D^{2}}{4}(\pi-2 \beta) \cdot 2 r^{\prime} \cdot \sin \left((\alpha(h))^{\prime}\right)+ \\
& 4 \int_{0}^{E A} \sigma_{0} \operatorname{Darcsin}\left(\frac{2 \alpha(x) \cdot r \cdot(d-\delta(x))}{\alpha(x)^{2} \cdot r^{2}+(d-\delta(x))^{2}}\right) d x
\end{aligned}
$$

According to Equation (40), the relationship between casing deformation and load under local lateral load can be calculated and analyzed.

\section{Example Analysis}

The second and third sections of the Qing formation in the Songliao basin were selected as the research object to verify the mechanical model of plastic failure of casing proposed above. Combined with the well group condition of actual casing collapse deformation in the Fuyu area of the Jilin oilfield,

\begin{tabular}{|c|c|c|c|c|c|c|c|c|}
\hline $\begin{array}{l}\text { Casing } \\
\text { Type }\end{array}$ & $\begin{array}{c}\text { Thickness } \\
\text { D/mm }\end{array}$ & $\begin{array}{c}\text { Yield } \\
\text { Stress } \\
\sigma_{0} / \mathbf{k N}\end{array}$ & $\begin{array}{c}\text { Plastic } \\
\text { Deformation } \\
\text { Length } 2 \mathrm{~h} / \mathrm{m}\end{array}$ & $\begin{array}{l}\text { Maximum } \\
\text { Deformation } \\
\text { Quantity } \\
\delta(h) / \mathrm{mm}\end{array}$ & $\begin{array}{c}\text { Local } \\
\text { Lateral } \\
\text { Load/MPa }\end{array}$ & $\begin{array}{l}\text { Collapsing } \\
\text { Strength } \\
\text { of } \\
\text { API/MPa }\end{array}$ & $\begin{array}{c}\text { Reduction } \\
\text { Value of } \\
\text { Intensity } \\
/ \mathrm{MPa}\end{array}$ & $\begin{array}{c}\text { Relative } \\
\text { Reduction } \\
\text { Ratio of } \\
\text { Intensity/\% }\end{array}$ \\
\hline \multirow{3}{*}{$5 \frac{1}{2} " J 55$} & 6.20 & 988 & 0.2 & 1.60 & 15.41 & 21.5 & 6.09 & 28.34 \\
\hline & 6.99 & 1103 & 0.2 & 1.42 & 22.59 & 27.9 & 5.31 & 19.04 \\
\hline & 7.72 & 1215 & 0.2 & 1.33 & 30.36 & 33.9 & 3.54 & 10.44 \\
\hline \multirow{3}{*}{$5 \frac{1}{2}{ }^{\prime \prime} \mathrm{N} 80$} & 7.72 & 1766 & 0.2 & 1.30 & 28.23 & 43.3 & 15.07 & 34.80 \\
\hline & 9.17 & 2073 & 0.2 & 1.00 & 48.54 & 60.9 & 12.36 & 20.30 \\
\hline & 10.54 & 2358 & 0.2 & 1.00 & 71.82 & 76.9 & 5.08 & 6.60 \\
\hline \multirow{3}{*}{$4 \frac{1}{2} " \mathrm{~J} 55$} & 5.21 & 676 & 0.2 & 1.85 & 12.75 & 22.8 & 10.05 & 44.09 \\
\hline & 5.69 & 734 & 0.2 & 1.78 & 18.46 & 27.6 & 9.14 & 33.12 \\
\hline & 6.35 & 819 & 0.2 & 1.56 & 25.58 & 34.2 & 8.62 & 25.20 \\
\hline \multirow{3}{*}{$4 \frac{1}{2}{ }^{\prime \prime} \mathrm{N} 80$} & 7.52 & 1557 & 0.2 & 1.39 & 31.60 & 50.0 & 18.4 & 36.80 \\
\hline & 9.19 & 1878 & 0.2 & 1.24 & 57.85 & 72.4 & 14.55 & 20.10 \\
\hline & 11.1 & 2229 & 0.2 & 1.00 & 87.12 & 88.0 & 0.88 & 1.00 \\
\hline
\end{tabular}
four types of casing, $4 \frac{1}{2}$ "J J55, $5 \frac{1}{2}$ "'J55, $4 \frac{1}{2}$ "N80 and $5 \frac{1}{2}$ "N80, with three kinds of wall thickness were calculated respectively for the well group of this section. The corresponding parameters and the results of the calculation are shown in Table 1.

Table 1. Results of local lateral load for casings with different wall thicknesses.

The results show that the bearing capacity when the casing string incurs deformation failure is significantly less than the collapsing strength of the API standard design under local lateral load, which illustrates that the main trigger of casing failure is the reduction of collapse strength (intensity) induced by local lateral load. It is therefore essential to propose a design scheme for collapsing strength under local lateral load for similar formation conditions.

As shown in Table 1, under local lateral loads, four types of casing collapse occur under external loads significantly lower than the collapse strength of API 5C3 standard. Further analysis shows that the plastic hinge formed in the deformation area of casing under local lateral load is the main 
reason for the decrease of casing collapsing strength and collapse deformation. Without doubt, when the casing is subjected to local lateral load, the design of casing collapsing strength based on current API 5C3 standard cannot meet the design requirements. Therefore, it is necessary to form new casing strength design standards and control schemes to prevent casing damage according to such formation conditions.

In order to clarify the internal relationship between casing deformation and lateral load, four types of casing $\left(4 \frac{1}{2}{ }^{\prime \prime} \mathrm{J} 55,5 \frac{1}{2}{ }^{\prime \prime} \mathrm{J} 55,4 \frac{1}{2}{ }^{\prime \prime} \mathrm{N} 80\right.$ and $\left.5 \frac{1}{2}{ }^{\prime \prime} \mathrm{N} 80\right)$ with three kinds of wall thickness in the Fuyu block of the Jilin oilfield were selected to calculate and analyze the relationship of casing intensity, the absolute reduction value of intensity and the relative reduction ratio of intensity change with casing wall thickness, yield stress, maximum deformation and the deformation length. The concrete results are summarized in Figures 13-30.

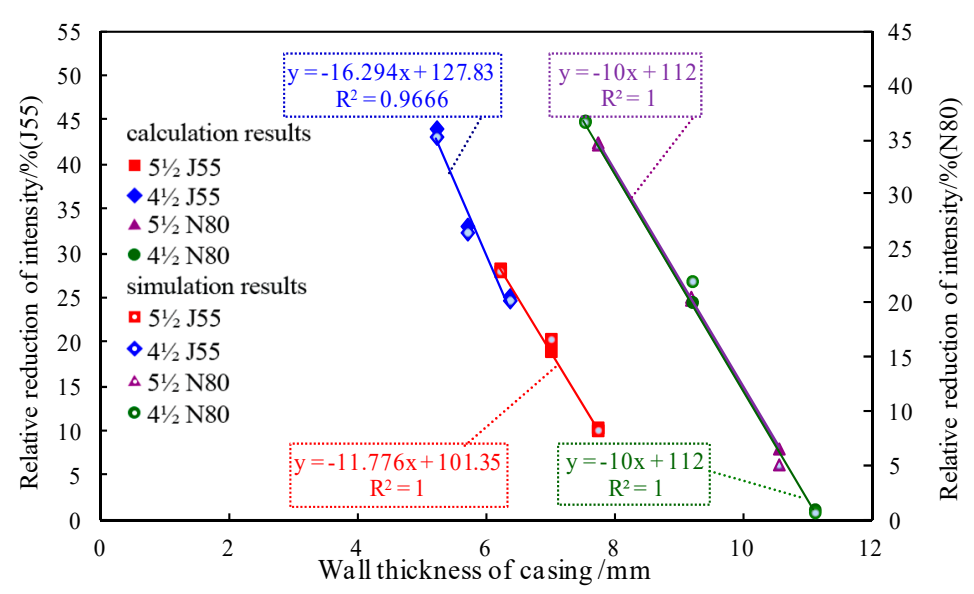

Figure 13. Relation between relative reduction ratio of intensity and wall thickness.

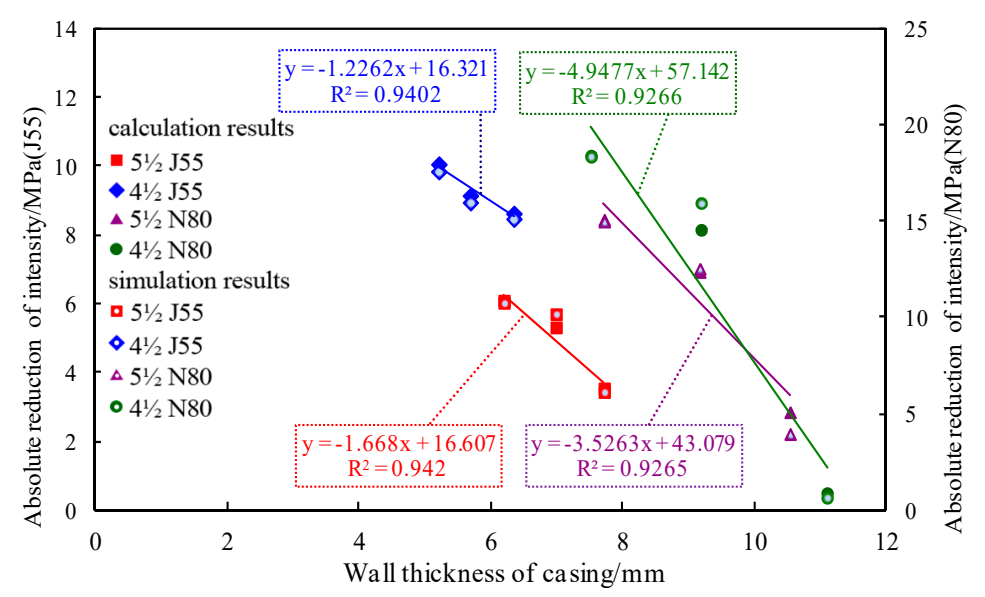

Figure 14. Relation between absolute reduction value of intensity and wall thickness.

The results shown in Figures 13-18 give the change regulations for the absolute reduction value of intensity (API 5C3 standard collapsing strength) and the relative reduction ratio of intensity (the percentage of the absolute reduction value of intensity to API 5C3 collapsing strength) when the wall thickness of the casing, the yield stress and the maximum deformation quantity change. The results show that the relative reduction ratio of intensity and the absolute reduction value of intensity decrease when the wall thickness of the casing and the yield stress increase, while they increase with increased maximum deformation and the relative reduction ratio of intensity changes approximately linearly. The results also show that the larger the wall thickness and the yield stress, the smaller the maximum deformation, and the smaller the reduction of intensity when the casing incurs deformation. That is 
to say, increasing the casing wall thickness and the yield stress, and taking measures early to control casing deformation, can effectively prevent the problem of lateral load-induced casing failure.

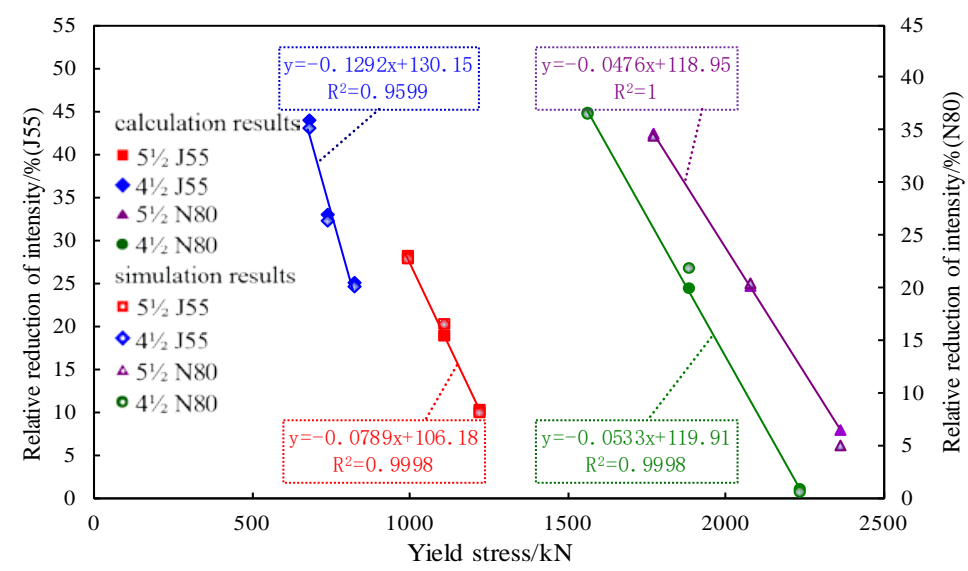

Figure 15. Relation between relative reduction ratio of intensity and yield stress.

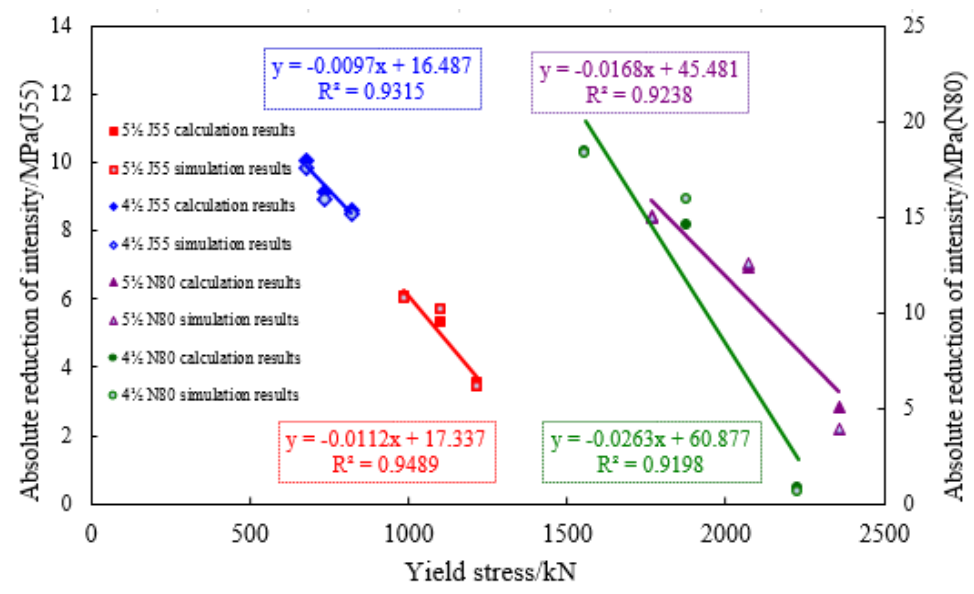

Figure 16. Relation curve between absolute reduction value of intensity and yield stress.

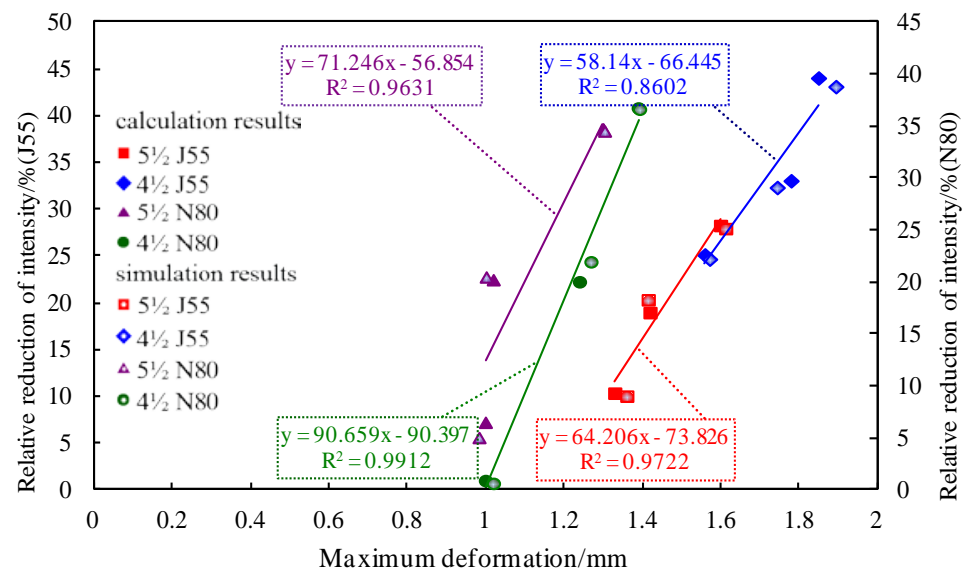

Figure 17. Relation between relative reduction ratio of intensity and maximum deformation.

The results shown in Figures 19 and 20 show that the bearing capacity of the casing increases with the increasing casing wall thickness and yield stress. According to the deformation of four types of casing in the Jilin oilfield, the bearing capacity of the casing has an approximately linear relation with the casing wall thickness and changing yield stress. This provides a scientific basis for the judgment of casing bearing capacity with changes in wall thickness and yield stress when other types of casing 
undergo similar failure. The result of Figure 21 show that the thicker the wall thickness, the smaller the deformation angle of the casing for the same type of steel with the increase of local lateral load.

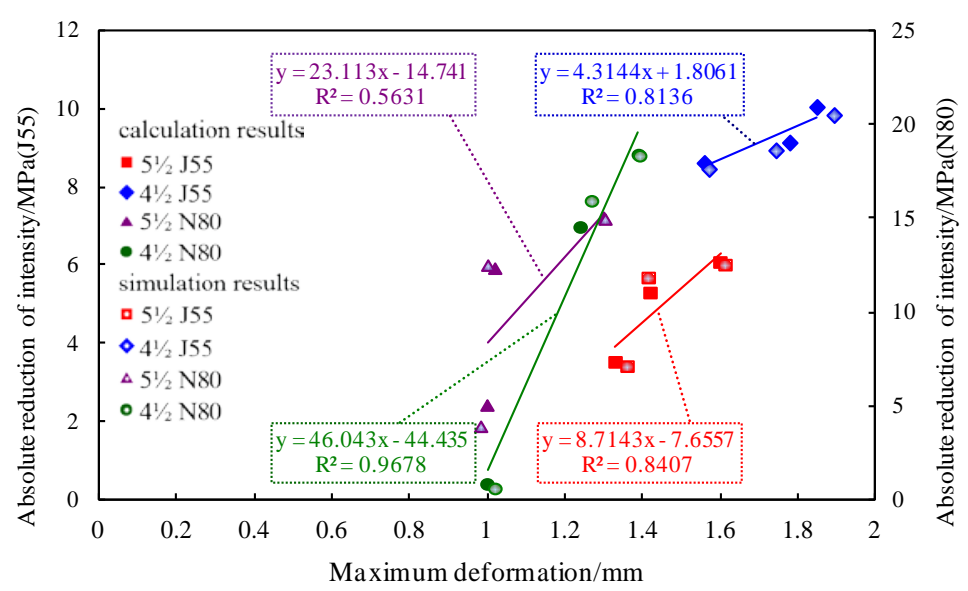

Figure 18. Relation between absolute reduction value of intensity and maximum deformation.

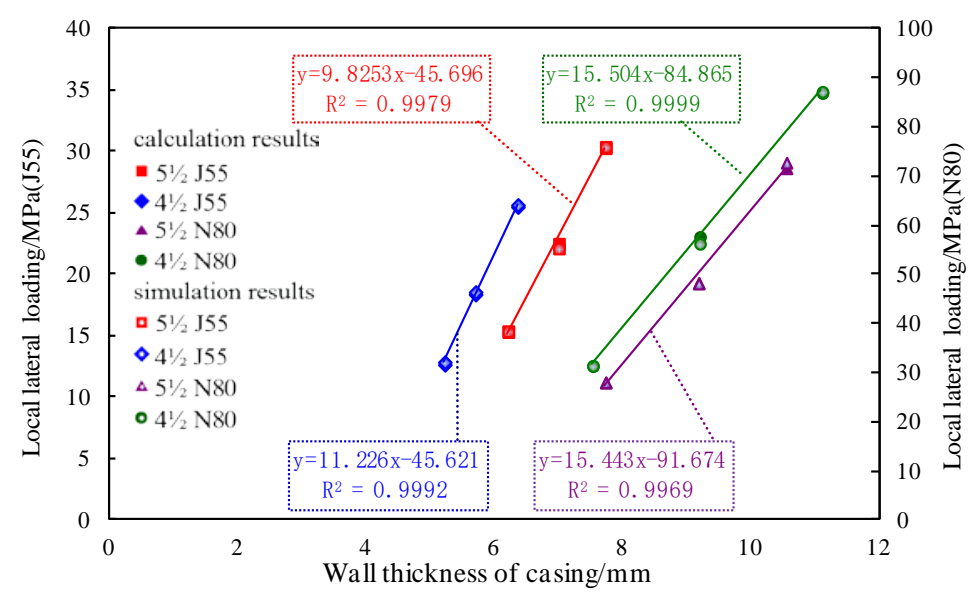

Figure 19. Relation between local lateral load and wall thickness of casing.

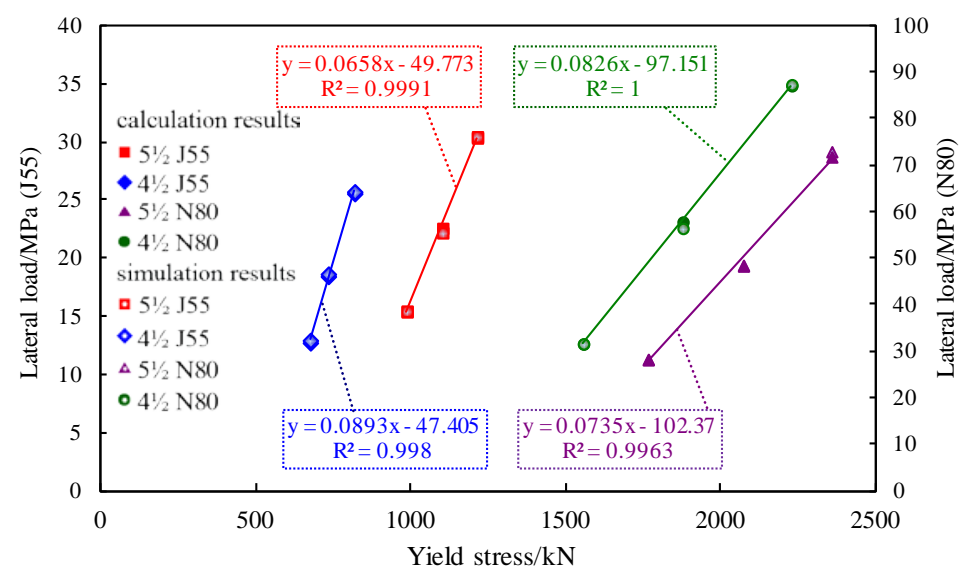

Figure 20. Relation between local lateral load and yield stress of casing. 


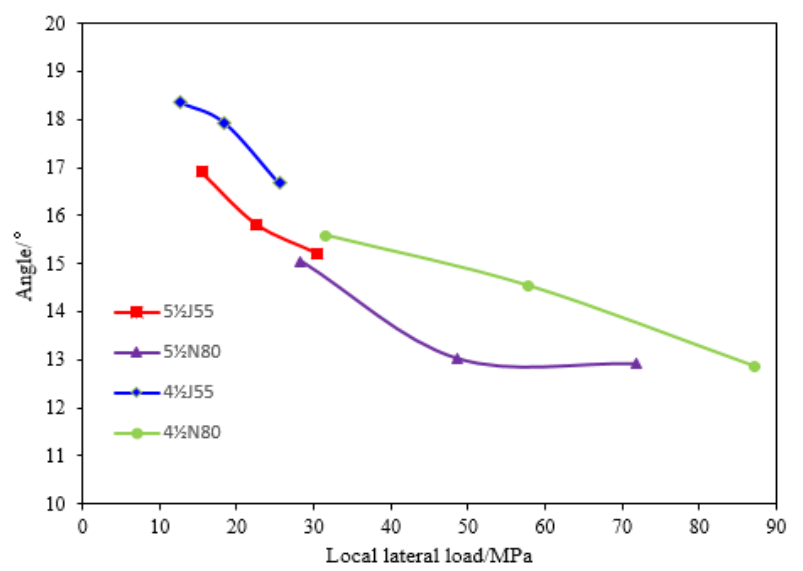

Figure 21. Relationship between local lateral load and angle.

In order to verify the casing deformation, finite element simulation was carried out. The results displayed in Figure 22 show that casings of the same steel type have the same elastic modulus. When the same load is applied, the casing deformation is the same. When the wall thickness of the casing is different, the deformation of the casing decreases with the increasing load. The casing deformation of four types under local lateral load based on finite element simulation is consistent with the analysis results of virtual working principle. Therefore, when the loads are the same, the deformation of the casing gradually decreases with the increase of the wall thickness of the casing. Relevant simulation material parameters are shown in Table 2.

Table 2. Related simulation material parameters.

\begin{tabular}{|c|c|c|c|c|c|c|c|}
\hline $\begin{array}{l}\text { Casing } \\
\text { Type }\end{array}$ & Thickness/mm & $\begin{array}{c}\text { External } \\
\text { Diameter/mm }\end{array}$ & $\begin{array}{l}\text { Local Lateral } \\
\text { Load/MPa }\end{array}$ & $\begin{array}{c}\text { Young's } \\
\text { Modulus/MPa }\end{array}$ & $\begin{array}{l}\text { Poisson's } \\
\text { Ratio }\end{array}$ & Density $/ \mathrm{g} / \mathrm{cm}^{3}$ & Angle/ ${ }^{\circ}$ \\
\hline \multirow{3}{*}{$5 \frac{1}{2} \mathrm{~J} 55$} & 6.20 & 76.05 & 15.41 & $2.03 \times 10^{5}$ & 0.3 & 7.8 & 16.905788 \\
\hline & 6.99 & 76.84 & 22.59 & $2.03 \times 105$ & 0.3 & 7.8 & 15.812929 \\
\hline & 7.72 & 77.57 & 30.36 & $2.03 \times 10^{5}$ & 0.3 & 7.8 & 15.215541 \\
\hline \multirow{3}{*}{$5 \frac{1}{2} \mathrm{~N} 80$} & 7.72 & 77.57 & 28.23 & $2.07 \times 10^{5}$ & 0.28 & 7.87 & 15.038393 \\
\hline & 9.17 & 79.02 & 48.54 & $2.07 \times 10^{5}$ & 0.28 & 7.87 & 13.025594 \\
\hline & 10.54 & 80.39 & 71.82 & $2.07 \times 10^{5}$ & 0.28 & 7.87 & 12.911906 \\
\hline \multirow{3}{*}{$4 \frac{1}{2} \mathrm{~J} 55$} & 5.21 & 75.06 & 12.75 & $2.03 \times 10^{5}$ & 0.3 & 7.8 & 18.348888 \\
\hline & 5.69 & 75.54 & 18.46 & $2.03 \times 10^{5}$ & 0.3 & 7.8 & 17.926281 \\
\hline & 6.35 & 76.2 & 25.58 & $2.03 \times 10^{5}$ & 0.3 & 7.8 & 16.669382 \\
\hline \multirow{3}{*}{$4 \frac{1}{2} \mathrm{~N} 80$} & 7.52 & 77.37 & 31.6 & $2.07 \times 10^{5}$ & 0.28 & 7.87 & 15.585058 \\
\hline & 9.19 & 79.04 & 57.85 & $2.07 \times 10^{5}$ & 0.28 & 7.87 & 14.537777 \\
\hline & 11.1 & 80.95 & 87.12 & $2.07 \times 10^{5}$ & 0.28 & 7.87 & 12.866283 \\
\hline
\end{tabular}

The results presented in Figures 23-26 show that the bearing capacity decreases with the increase of the deformation length, and the variation law of the four types of casing is similar. When deformation length of casing is less than the critical value, the bearing capacity decreases rapidly and the curve changes steeply as deformation length increases. When the deformation length reaches the critical value, the bearing capacity of casing decreases slowly, approximating constant value. Therefore, the casing deformation should be prevented as early as possible when deformation length is less than the critical value. 


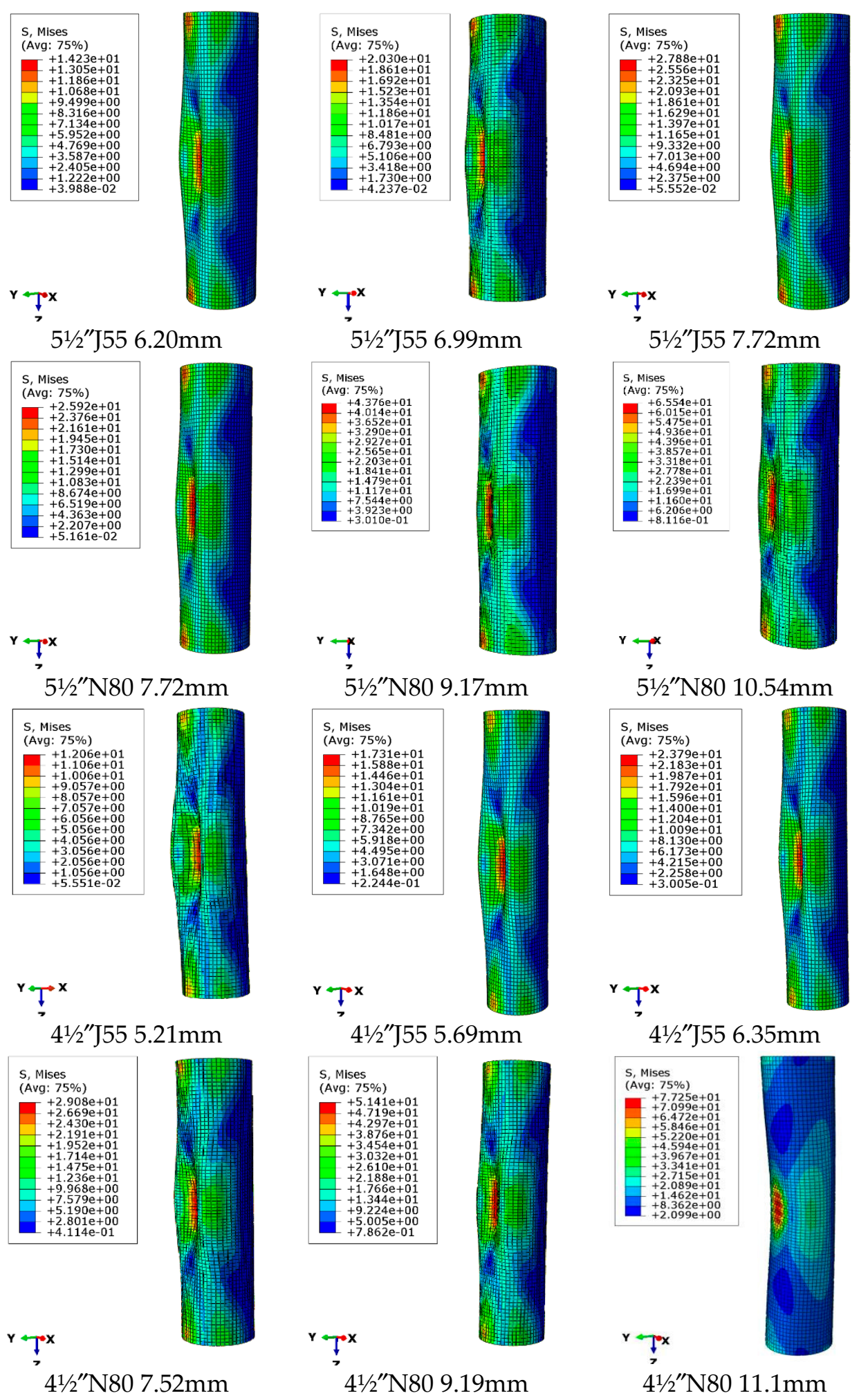

Figure 22. Finite element simulation of casing deformation under local lateral load. 


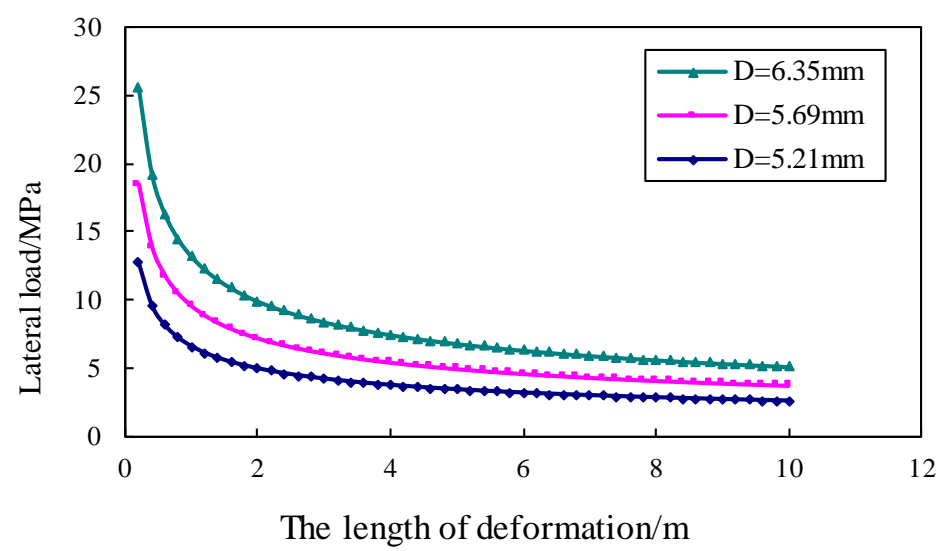

Figure 23. Relation between local lateral load and deformation length for $4 \frac{1}{2} \mathrm{~J} 55$ casing.

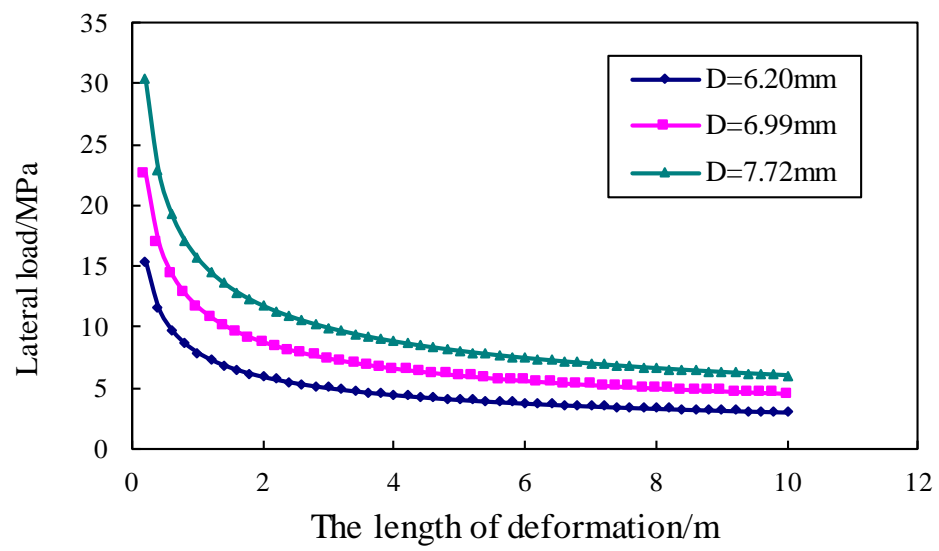

Figure 24. Relation between local lateral load and deformation length for $5 \frac{1}{2} \mathrm{~J} 55$ casing.

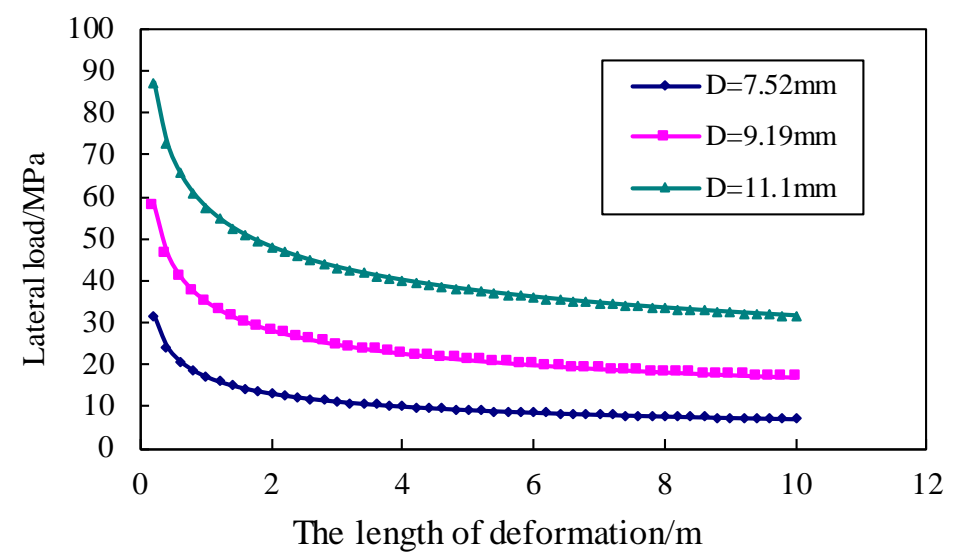

Figure 25. Relation between local lateral load and deformation length for $4 \frac{1}{2} \mathrm{~N} 80$ casing.

The results presented in Figures 27-30 show that the bearing capacity of casing decreases as the maximum deformation increases. When the maximum deformation is less than the critical value, the bearing capacity of casing decreases rapidly. On the contrary, the reduction of the bearing capacity of casing is smaller, and the bearing capacity of different wall thickness casing is approximately equal, that is to say, increasing the thickness of casing cannot prevent the occurrence of casing collapse when deformation reaches a certain value. Therefore, in order to effectively control casing failure, preventive measures should be carried out when radial deformation of casing is smaller. 


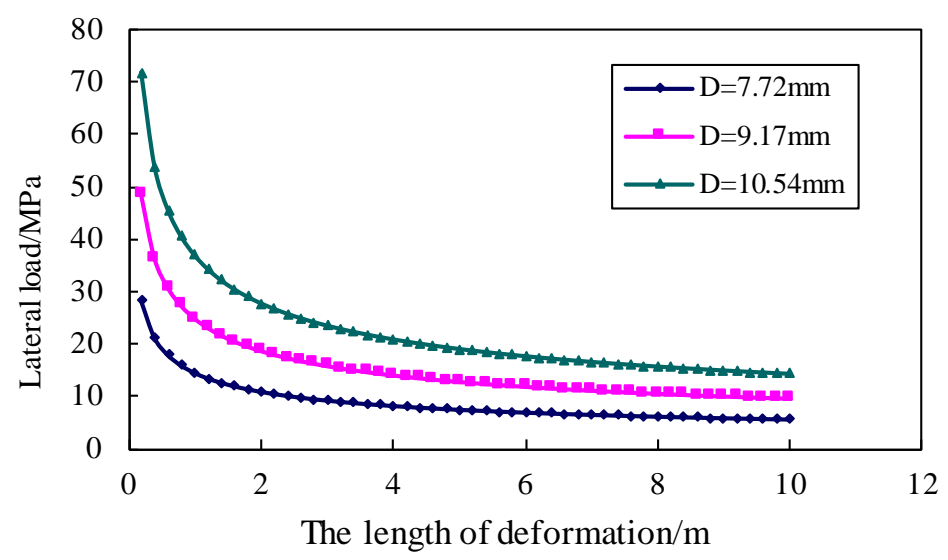

Figure 26. Relation between local lateral load and deformation length for $5 \frac{1}{2} \mathrm{~N} 80$ casing.

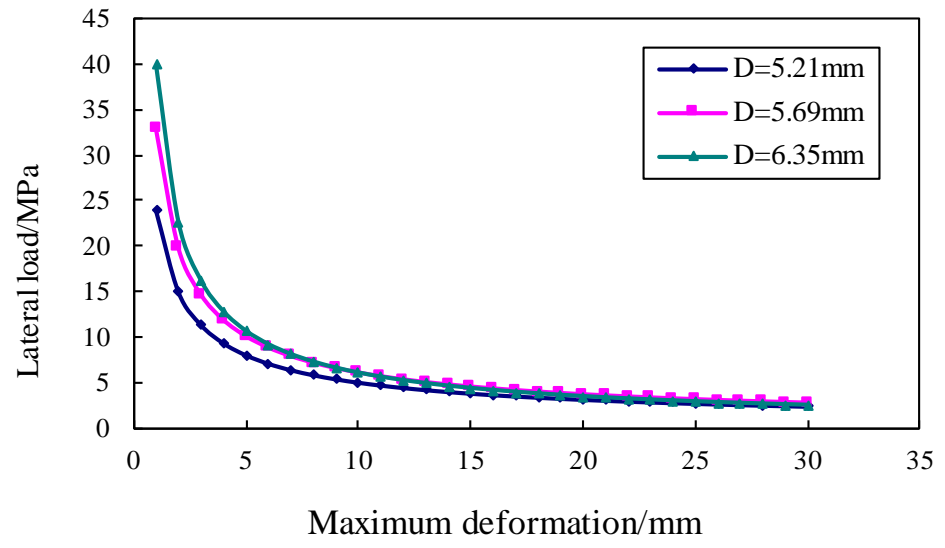

Figure 27. Relation between local lateral load and maximum deformation for $4 \frac{1}{2} \mathrm{~J} 55$ casing.

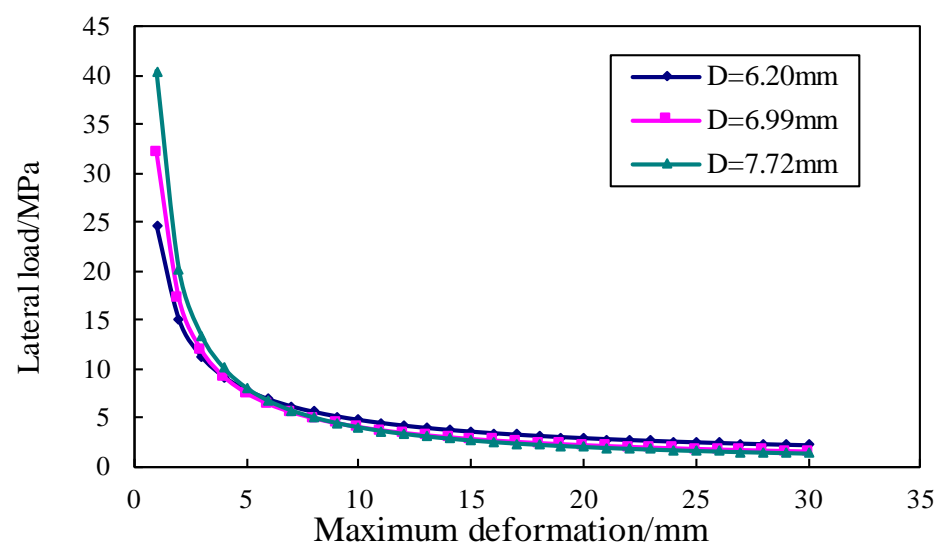

Figure 28. Relation between local lateral load and maximum deformation for $5 \frac{1}{2} \mathrm{~J} 55$ casing. 


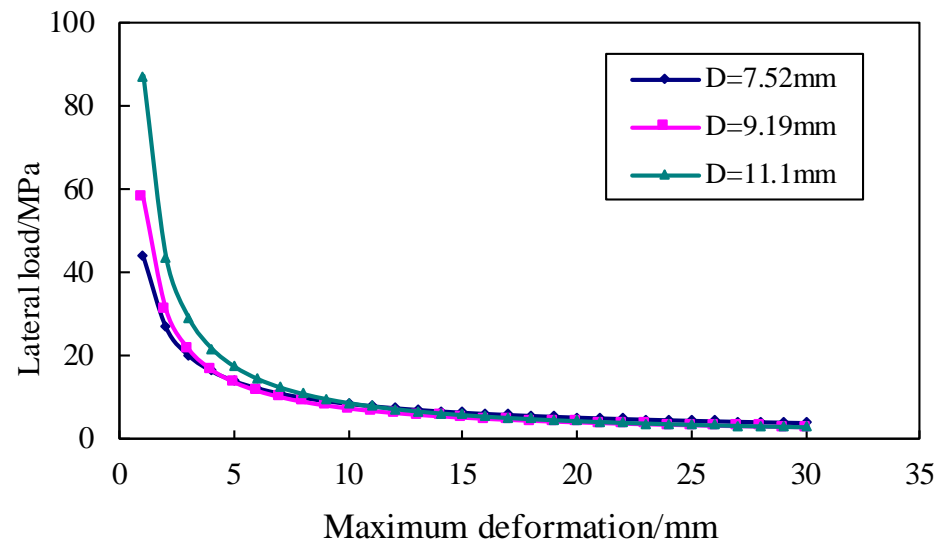

Figure 29. Relation between local lateral load and maximum deformation for $4 \frac{1}{2} \mathrm{~N} 80$ casing.

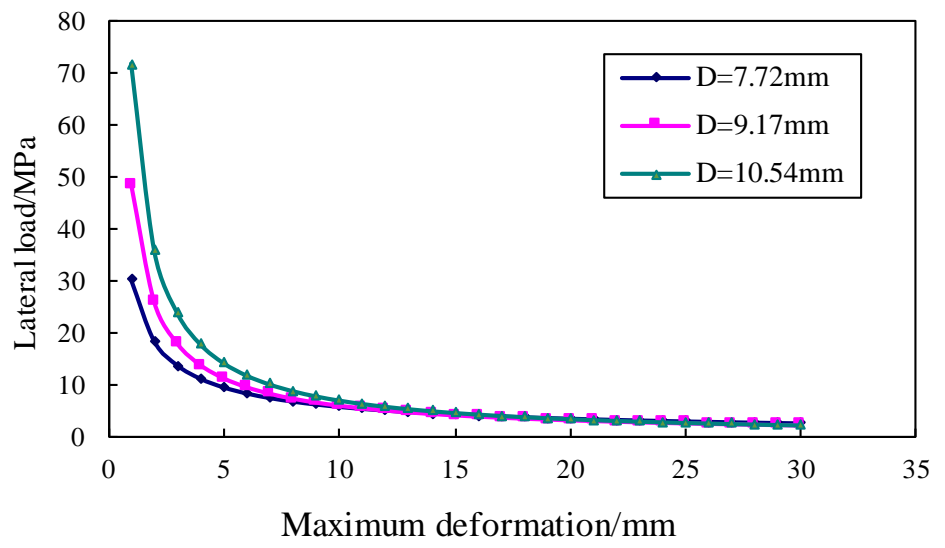

Figure 30. Relation between local lateral load and maximum deformation for $5 \frac{1}{2} \mathrm{~N} 80$ casing.

\section{Conclusions}

1. According to the actual collapse deformation characteristics of the casing in the oilfield, the yield surface of the casing collapse deformation is considered as a plane plastic zone with an arc-shaped boundary. The internal work of the casing is equal to the external work of the casing in the process of casing collapse deformation. In this paper, a mechanical model and a calculation method for the local lateral collapse deformation of the casing are presented based on the principle of virtual work.

2. The bearing capacity when the casing string incurs deformation failure is significantly less than the collapsing strength of the API SPEC 5CT standard design under local lateral load, which illustrates that the main trigger of casing failure is the reduction of collapse strength (intensity) induced by local lateral load. According to the results for the selected examples, the maximum absolute reduction value of intensity is $14.55 \mathrm{MPa}$, and the maximum relative reduction ratio of intensity is $44.09 \%$. Therefore, the design standard of API collapsing strength is not suitable for the local load of casing, and it is necessary to develop new collapsing strength designs under local lateral load.

3. According to the results, the relative reduction ratio of intensity and the absolute reduction value of intensity decline with the increase of wall thickness of the casing and yield stress. They will also increase with the increase of maximum deformation. They change approximately linearly.

4. The results show that the casing bearing capacity decreases rapidly with the increase of the length of the deformation and the radial deformation amount in the initial stage. Moreover, the influence of the radial deformation is greater than that of the length of deformation on the bearing capacity of the casing. Therefore, the measures should be proposed as soon as possible, and controlling 
radial deformation of casing will be more significant to prevent casing collapse for formations under local lateral loading.

Author Contributions: Individual contributions: conceptualization, W.Z. and R.P.G.; methodology, W.Z. and Z.S.; software, J.G. and Z.S.; validation, J.G. and Z.S.; formal analysis, Y.L.; investigation, W.Z. and J.G.; resources, W.Z. and T.W.; data curation, J.G. and Z.S.; writing—original draft preparation, W.Z. and J.G.; writing—review editing, J.G. and Z.S.; visualization, Y.L. and T.W.; supervision, W.Z. and R.P.G.; project administration, W.Z.; funding acquisition, W.Z. and Y.L.

Funding: This research was supported by the Talented Reserves of Heilongiiang Province Science Foundation for Distinguished Young Scholars of Northeast Petroleum University (SJQHB201802), National Natural Science Foundation of China (Grant No. 51404073, Grant No. 51574088), Natural Science Foundation of Heilongjiang Province of China (Young Scientists) (Grant No. QC2017043), 9th special China Postdoctoral science Foundation projects (Grant No. 2016T90268), Heilongjiang Postdoctoral Foundation (LBH-TZ-0503), China Postdoctoral Science Foundation (Grant No. 2018M630335), Heilongjiang General Undergraduate Colleges and Universities Young Innovative Talents Training Plan (Grant No. UNPYSCT-2016084), Key Young Project of Northeast Petroleum University "National Foundation" Cultivating foundation (Science) 2017.

Conflicts of Interest: The authors declare no conflicts of interest. To the best of our knowledge, the named authors have no conflict of interest, financial or otherwise.

\section{References}

1. Lian, Z.H.; Yu, H.; Lin, T.J.; Guo, J.H. A study on casing deformation failure during multi-stage hydraulic fracturing for the stimulated reservoir volume of horizontal shale wells. J. Nat. Gas Sci. Eng. 2015, 23, 538-546. [CrossRef]

2. Yan, W.; Zou, L.Z.; Li, H.; Deng, J.; Ge, H.; Wang, H. Investigation of Casing Deformation during Hydraulic Fracturing in High Geo-Stress Shale Gas Play. J. Pet. Sci. Eng. 2016, 150, 22-29. [CrossRef]

3. Li, L.W.; Wang, G.C.; Zhang, H.; Zhang, L.; Mei, J.; He, Y. Deformation mechanism of horizontal shale gas well production casing and its engineering solution: A case study on the Huangjinba Block of the Zhaotong National Shale Gas Demonstration Zone. Nat. Gas Ind. 2017, 37, 91-99. [CrossRef]

4. Liu, K.; Gao, D.L.; Wang, Y.B.; Yang, Y.C. Effect of local loads on shale gas well integrity during hydraulic fracturing process. J. Nat. Gas Sci. Eng. 2017, 37, 291-302. [CrossRef]

5. Lin, T.J. Casing failure mechanism during volume fracturing: A case study of a shale gas well. Adv. Mech. Eng. 2017, 9, 1-9. [CrossRef]

6. American Petroleum Institute. Bulletin on formulars and calculations for casing, tubing, drill pipe and line properties. In API Bulletin 5C3, 6th ed.; API: Washington, DC, USA, 1994.

7. Lin, Y.H.; Deng, K.H.; Sun, Y.X.; Zeng, D.Z. Collapse pressure of casing wall based on uniform strength theory. Pet. Explor. Dev. 2016, 43, 462-468. [CrossRef]

8. Klever, F.J.; Tamano, T. A new OCTG strength equation for collapse under combined loads. SPE Drill. Complet. 2006, 21, 164-179. [CrossRef]

9. Klever, F. A design strength equation for collapse of expanded OCTG. SPE Drill. Complet. 2010, 25, 391-408. [CrossRef]

10. Greenip, J.F. Collapse Strength of Casing Subjected to Combined Load. In Proceedings of the IADC/SPE Drilling Conference and Exhibition, Fort Worth, TX, USA, 1-3 March 2016; pp. 1-11.

11. Zhao, J.H.; Li, Y.; Zhang, C.G.; Xu, J.; Wu, P. Collapsing strength for petroleum casing string based on unified strength theory. Acta Pet. Sin. 2013, 34, 969-976.

12. Cai, Z.M.; Zhang, J.; Shen, Z.T.; Jin, M.C.; Zhang, S.J. Effect of Ovality on Collapse Strength of Casing Pipe Under Non-Uniform Loading. Oil Field Equip. 2010, 39, 20-23.

13. International Organization for Standardization. Petroleum and natural gas industries-Formulae and calculation for casing, tubing, drill pipe and line pipe properties. In ISO 10400, 6th ed.; ISO: Geneva, Switzerland, 1993.

14. Han, J.Z. Research on Casing Collapse Resistance; Southwest Petroleum Institute: Chengdu, China, 2001.

15. Pattillo, P.D.; Last, N.C.; Asbill, W.T. Effect of nonuniform loading on conventional casing collapse resistance. SPE Drill. Complet. 2004, 19, 156-163. [CrossRef] 
16. Yin, Y.Q.; Cai, Y.G.; Chen, Z.W.; Liu, J.S. Theoretical solution of casing loading in non-uniform ground stress field. Acta Pet. Sin. 2006, 27, 133-138.

17. Zhang, Z.; Xu, B.H.; Shi, T.H.; Wu, Y.; Chen, J.F. Application of Reliability Design Theory in Casing String Design. West China Explor. Eng. 2007, 19, 49-51.

18. Sun, C.; Wang, J.; Liu, C.S. Analysis of casing damage factors and preventive measures in Jilin oilfield. Nat. Gas Oil 2011, 2, 43-47.

19. Ai, C.; Zhao, W.C.; Guo, B.Y. Mechanical Model and Computational Analysis of Casing Plastic Failure Underlateral Loading. Chin. J. Appl. Mech. 2008, 25, 521-524.

20. Ai, C. Mechanism and Theoretic Models of Casing Failure and Numerical Calculation with Them; Daqing Petroleum Institute: Daqing, China, 2003.

21. Zhao, Y.S.; Zhang, J.; Luo, Y.S.; Li, J.; Tang, D.Z. Effects of Hf and B on high temperature low stress creep behavior of a second generation Ni based Single crystal superalloy DD01. Mater. Sci. Eng. A 2016, 672, 143-152. [CrossRef]

22. Jones, N.; Shen, W.Q.; Birch, R.S.; Zhu, L.; Brown, M. An experimental study on the lateral impact of fully clamped mild steel pipes. J. Process Mech. Eng. 1992, 206, 111-127. [CrossRef]

23. Ding, H.; Zu, Q.; Feng, Z. Dynamic analysis of a new forging manipulator's main motion mechanism based on the principle of virtual work. J. Mech. Eng. 2016, 52, 18-27. [CrossRef]

24. Strydom, J.H.; Elvin, A. Optimizing the design of steel bridges using the principle of virtual work. In Insights and Innovations in Structural Engineering, Mechanics and Computation: Proceedings of the 6th International Conference on Structural Engineering, Mechanics and Computation; CRC Press: Boca Raton, FL, USA, 2016; pp. 1184-1189.

25. Pedrammehr, S.; Nahavandi, S.; Abdi, H. Closed-form dynamics of a hexarot parallel manipulator by means of the principle of virtual work. Acta Mech. Sin. 2018, 34, 883-895. [CrossRef]

26. Elvin, A.; Strydom, J. Optimizing Structures with Semi-Rigid Connections Using the Principle of Virtual Work. Int. J. Steel Struct. 2018, 18, 1006-1017. [CrossRef]

27. Zhong, J.; Xie, Z.; Shen, D.; Xu, Z. Load and Displacement Transfer Method Based on Virtual Work Principle for Fluid Structure Interaction. His Chiao Tung Ta Hsueh J. Xian Jiaotong Univ. 2018, 52, 160-167.

28. Wang, H.D. Further discussion on the principle of virtual work of deformable body. Mech. Eng. 2011, 33, 93-95.

29. Rondeaux, J.F.; Zastavni, D. Limit state analysis of historical structures using graphic statics related to the principle of virtual works. In Structural Analysis of Historical Constructions: Anamnesis, Diagnosis, Therapy, Controls: Proceedings of the 10th International Conference on Structural Analysis of Historical Constructions; CRC Press: Boca Raton, FL, USA, 2016; pp. 1246-1253.

30. Sepahvand, M.F.; Akbari, J. Toward seismic design of tall steel moment resisting frames using the theory of plastic mechanism control. J. Build. Eng. 2019, 24, 100750. [CrossRef]

31. Sepahvand, M.F.; Akbari, J.; Kusunoki, K. Plastic design of moment resisting frames using mechanism control. J. Constr. Steel Res. 2019, 153, 275-285. [CrossRef]

32. Muscati, R. MRFs Designed According to the Theory of Plastic Mechanism Control vs. Code Rules. Available online: https://pdfs.semanticscholar.org/ec4c/06512aeb7d6f60eb7afde96eb7c2814e6ab6.pdf (accessed on 28 September 2019).

33. Kazemi, M.T.; Sharifi, M.; Yang, J. Mechanism analysis of steel frames considering moment-shear interaction. Adv. Struct. Eng. 2019, 22, 254-267. [CrossRef]

34. Sepahvand, M.F.; Akbari, J.; Kusunoki, K. Optimum Plastic Design of Moment Resisting Frames Using. Mech. Control Struct. 2018, 16, 254-268.

35. Ntina, M.I.; Sophianopoulos, D.S. A new rate-dependent constitutive model of superelastic shape memory alloys and its simple application in a special truss moment frame simulation. Adv. Civ. Eng. 2018, 2018, 1634702. [CrossRef]

36. Xu, B.Y.; Huang, Y.; Liu, X.S.; Sun, X.W. Problem Solving Instruction and Exercise Set for Elasticity and Plasticity; Higher Education Press: Beijing, China, 1985; p. 23. 
37. Martin, J.B. The Basis of Plastic Mechanics and Its General Results; Beijing Institute of Technology Press: Beijing, China, 1990; p. 31.

38. Lu, W.-S.; Antoniou, A. Comments on "Author's reply on the 2-D unit noise matrix" by T. Hinamoto, et al.; and T. Lin, et al. IEEE Trans. Circuits Syst. 1988, 35, 611-612. [CrossRef] 